\title{
Long-term urodynamic evaluation of laparoscopic radical cystectomy with orthotopic ileal neobladder for bladder cancer
}

\author{
DONG WANG, LI-JUN LI, JING LIU and MING-XING QIU \\ Department of Urology, Sichuan Academy of Medical Sciences and Sichuan Provincial People's Hospital, \\ Chengdu, Sichuan 610072, P.R. China
}

Received November 23, 2013; Accepted May 23, 2014

DOI: 10.3892/ol.2014.2281

\begin{abstract}
The long-term urodynamics of laparoscopic radical cystectomy with orthotopic ileal neobladder for bladder cancer remain unclear in the clinical setting. The present prospective observational study was conducted between January 2010 and December 2012 to evaluate the 6-month and 12-month follow-up data of urodynamic changes of bladder cancer patients who were initially treated by laparoscopic radical cystectomy with orthotopic ileal neobladder. A total of 53 eligible patients were included, and all patients were followed up for at least 12 months, with a median time of 18 months. During the follow-up period, no patients reported difficulty urinating, and the daily frequency of urination and the urine output were gradually improved with time. Dynamic urodynamic examinations showed that the maximum flow rate $(11.4 \pm 1.1$ vs. $7.3 \pm 1.4 \mathrm{ml} / \mathrm{sec} ; \mathrm{P}<0.001)$, residual urine content $(22.8 \pm 10.5$ vs. $40.7 \pm 12.7 \mathrm{ml} ; \mathrm{P}<0.001)$, maximum bladder capacity $(373.8 \pm 62.2$ vs. $229.7 \pm 56.3 \mathrm{ml}$; $\mathrm{P}<0.001)$ and maximum bladder pressure during filling (35.8 \pm 6.7 vs. $26.4 \pm 7.0 \mathrm{~cm} \mathrm{H}_{2} \mathrm{O} ; \mathrm{P}<0.001$ ) at 12 months were all improved significantly compared with that at 6 months after the initial surgical treatment. However, there were no significant differences in maximum bladder pressure during voiding ( $75.7 \pm 24.7$ vs. $\left.73.1 \pm 24.7 \mathrm{~cm} \mathrm{H}_{2} \mathrm{O} ; \mathrm{P}=0.618\right)$ and bladder compliance $\left(26.9 \pm 13\right.$ vs. $\left.27.4 \pm 13.1 \mathrm{~cm} \mathrm{H}_{2} \mathrm{O} ; \mathrm{P}=0.848\right)$ at 12 and 6 months after initial surgical treatment. In conclusion, the urodynamics of this orthotopic ileal neobladder gradually improve, and its long-term urine storage and voiding functions are acceptable.
\end{abstract}

\section{Introduction}

Bladder cancer is a major health problem, particularly among males. It is estimated that in the year 2008, 150,000 patients

Correspondence to: Dr Li-Jun Li, Department of Urology, Sichuan Academy of Medical Sciences and Sichuan Provincial People's Hospital, 32 West Second Section First Ring Road, Chengdu, Sichuan 610072, P.R. China

E-mail: 1jli028@hotmail.com

Key words: urodynamics, laparoscopic radical cystectomy, orthotopic ileal neobladder, bladder cancer succumbed to bladder cancer and 386,300 new patients were diagnosed throughout the world (1). In the USA, bladder cancer is the fifth most common malignancy (2). According to a critical systematic review, bladder cancer is the most expensive malignancy to treat on a per-patient basis due to the requirement for lifelong routine monitoring and treatment from diagnosis to mortality $(3,4)$.

Over the past 10 years, great progress has been made in our understanding of bladder cancer $(5,6)$, and radical cystectomy with orthotopic ileal neobladder is frequently performed for muscle-invasive bladder cancer and high-risk superficial tumors that are unresponsive to intravesical therapy $(7,8)$. With the development of laparoscopic surgery in urology, laparoscopic radical cystectomy with different urinary diversions has been reported as a step by step procedure $(9,10)$. Another study has indicated that laparoscopic radical cystectomy with orthotopic ileal neobladder is feasible and provides a number of intraoperative and post-operative advantages over a traditional open approach (11), including decreasing the amount of intraoperative bleeding, reducing post-operative pain and complications, shortening the time required for recovery, and allowing low morbidity and oncological safety.

Although the surgical techniques of laparoscopic radical cystectomy with orthotopic ileal neobladder have been studied extensively, no previous study has examined the long-term urodynamic changes of this surgical procedure. Urodynamic testing or urodynamics assesses the ability of the bladder and urethra to store and release urine (12). The purpose of the present study was to determine the long-term urodynamics of laparoscopic radical cystectomy with orthotopic ileal neobladder for patients with bladder cancer. This long-term evaluation of urodynamics would also aid in promoting the recognition of this procedure as an effective standard treatment for bladder cancer.

\section{Patients and methods}

Patients and studydesign. This prospective observational study was conducted between January 2010 and December 2012. Bladder cancer patients who received laparoscopic radical cystectomy with orthotopic ileal neobladder in the Department of Urology, Sichuan Academy of Medical Sciences and Sichuan Provincial People's Hospital (Chengdu, Sichuan, China), were included, while bladder cancer patients who showed evidence 
Table I. Demographics and pre-operative clinical parameters.

\begin{tabular}{|c|c|}
\hline Parameters & Value \\
\hline \multicolumn{2}{|l|}{ Demographics } \\
\hline Age, years & $58.7 \pm 7.3$ \\
\hline Male/female, n (\%) & $51(96.2) / 2(3.8)$ \\
\hline Body mass index, $\mathrm{kg} / \mathrm{m}^{2}$ & $20.9 \pm 2.7$ \\
\hline \multicolumn{2}{|c|}{ History of open or abdominal/pelvic surgery, n (\%) } \\
\hline Partial cystectomy & $6(11.3)$ \\
\hline Cholecystectomy & $3(5.7)$ \\
\hline Repair of gastric perforation & $2(3.8)$ \\
\hline Partial gastrectomy & $2(3.8)$ \\
\hline Appendectomy & $1(1.9)$ \\
\hline \multicolumn{2}{|c|}{ Pre-operative clinical T-staging, n (\%) } \\
\hline $\mathrm{T} 1$ & $6(11.3)$ \\
\hline $\mathrm{T} 2 \mathrm{a}$ & $28(52.8)$ \\
\hline $\mathrm{T} 2 \mathrm{~b}$ & $10(18.9)$ \\
\hline $\mathrm{T} 3 \mathrm{~b}$ & $8(15.1)$ \\
\hline $\mathrm{T} 4 \mathrm{a}$ & $1(1.9)$ \\
\hline \multicolumn{2}{|c|}{ Pre-operative clinical N-staging, n (\%) } \\
\hline No & $49(92.5)$ \\
\hline N1 & $4(7.5)$ \\
\hline \multicolumn{2}{|c|}{ Pre-operative histological characteristics, n (\%) } \\
\hline Grade I/II/III & $7(13.2)$ \\
\hline Grade II & $42(79.2)$ \\
\hline Grade III & $4(7.5)$ \\
\hline
\end{tabular}

of distant metastases at diagnosis, complications with serious internal diseases or any other malignancies were all excluded.

This study was approved by the Institutional Review Board of the Sichuan Academy of Medical Sciences and Sichuan Provincial People's Hospital and was conducted in accordance with the 1975 Declaration of Helsinki. All patients signed informed consent forms prior to participating in this study.

Surgical procedures and urodynamic assessment. Prior to surgery, a complete physical examination and routine other examinations, including urodynamic testing and pre-operative examinations, such as cystoscopy, ultrasonography, abdominal and pelvic CT or MRI, were all performed. The laparoscopic radical cystectomy and orthotopic ileal neobladder procedures were performed by surgical specialists, and detailed information on the surgical procedures can be obtained from a previously published study (10). When discharged from hospital following surgery, all patients were prospectively followed up at a clinic in the Sichuan Academy of Medical Sciences and Sichuan Provincial People's Hospital for $>12$ months, and excretory urography and urodynamics were examined every 6 months.

In this study, urodynamic evaluations were performed using a Nidoc 970 A Urodynamic System (Yongxin Medical Equipment Co., Ltd., Chengdu, Sichuan, China), and the following urodynamic parameters were assessed: Maximum flow rate, residual urine, maximum bladder capacity, maximum bladder pressures during filling and voiding, and bladder compliance.

Statistical analysis. The storage and statistical analyses were performed using SPSS version 17.0 (SPSS, Inc., Chicago, IL, USA). Continuous data are presented as the mean \pm standard deviation, while categorical data are presented as $\mathrm{n}(\%)$. Comparisons of continuous data employed an independent two-sided paired t-test. $\mathrm{P}<0.05$ was considered to indicate a statistically significant difference.

\section{Results}

General information. As shown in Fig. 1, a total of 67 bladder cancer patients were screened in the present study, and only 53 patients were finally included; the other 14 patients were excluded from the statistical analysis for various reasons.

The detailed demographics, pre-operative surgical history and pre-operative stage parameters of the 53 included patients are all listed in Table I. The intraoperative events and short-term postoperative data of the patients are summarized in Table II, and indicated that laparoscopic radical cystectomy with extracorporeal formation of a neobladder are feasible and safe procedures for bladder cancer patients.

Changes in urodynamics. In order to investigate the long-term efficacy of laparoscopic radical cystectomy with orthotopic 
Table II. Intraoperative events and post-operative data.

\begin{tabular}{lc}
\hline Parameters & Value \\
\hline Duration of surgical procedures, min & $308.5 \pm 62.7$ \\
Estimated blood loss, ml & $210.5 \pm 106.8$ \\
Blood transfusion, $\mathrm{n}(\%)$ & $8(15.1)$ \\
Duration of intra-abdominal drainage, days & $3.2 \pm 1.4$ \\
Duration of foley catheter, days & $12.4 \pm 2.9$ \\
Duration of bilateral ureteral stent, days & $11.8 \pm 2.2$ \\
Bowel activity recovery time post-surgery, days & $3.1 \pm 1.8$ \\
Time until food intake post-surgery, days & $4.2 \pm 0.7$ \\
Hospitalization time post-surgery, days & $13.5 \pm 2.6$ \\
Follow-up time post-discharge, months & $17.6 \pm 5.3$ \\
Difficulty urinating during follow-up, $\mathrm{n}(\%)$ & $0(0.0)$
\end{tabular}

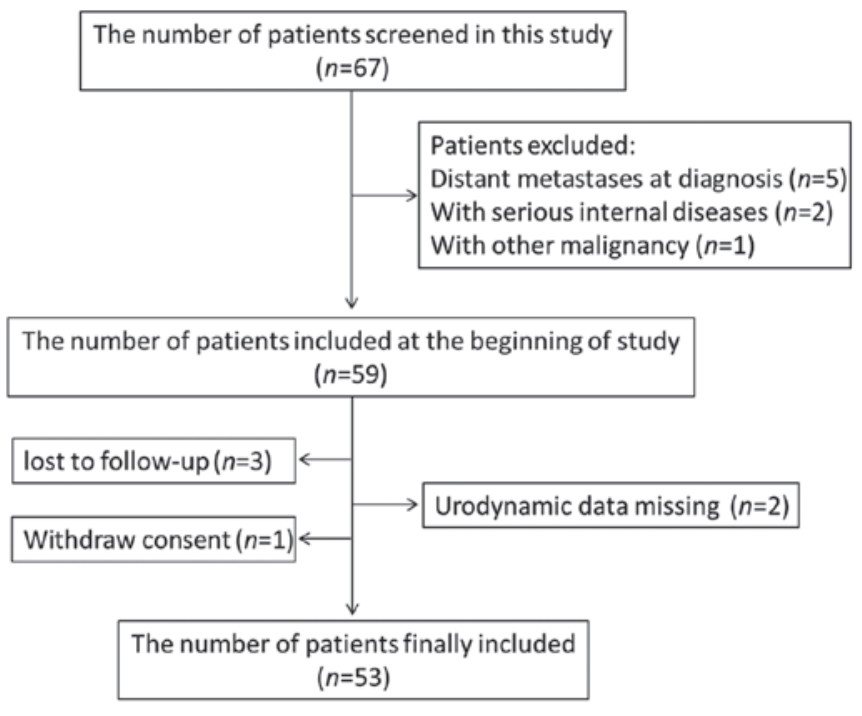

Figure 1. Flowchart of patient inclusion and exclusion.

ileal neobladder for bladder cancer, all patients were followed up for at least 12 months and the urodynamic improvement of the patients was evaluated. During the follow-up period, no patients reported difficulty in urinating (Table II), and the daily frequency of urination and the urine output gradually improved with time.

As shown in Fig. 2, there was a time-related continuous improvement in urodynamics. Compared with 6 months after the initial surgical treatment, the maximum flow rate $(11.4 \pm 1.1$ vs. $7.3 \pm 1.4 \mathrm{ml} / \mathrm{sec} ; \mathrm{P}<0.001)$, residual urine $(22.8 \pm 10.5$ vs. $40.7 \pm 12.7 \mathrm{ml} ; \mathrm{P}<0.001)$, maximum bladder capacity ( $373.8 \pm 62.2$ vs. $229.7 \pm 56.3 \mathrm{ml} ; \mathrm{P}<0.001)$ and maximum bladder pressure during filling (35.8 \pm 6.7 vs. $26.4 \pm 7.0 \mathrm{~cm} \mathrm{H}_{2} \mathrm{O}$; $\mathrm{P}<0.001)$ at 12 months had all improved significantly. However, there was no significant difference in either the maximum bladder pressures during voiding $(75.7 \pm 24.7$ vs. $73.1 \pm 24.7 \mathrm{~cm}$ $\left.\mathrm{H}_{2} \mathrm{O} ; \mathrm{P}=0.618\right)$ or bladder compliance $(26.9 \pm 13.6$ vs. $27.4 \pm 13$. $1 \mathrm{~cm} \mathrm{H}_{2} \mathrm{O} ; \mathrm{P}=0.848$ ) at 12 and 6 months after initial surgical treatment. These long-term dynamic improvements in urodynamics showed that the constructed neobladder had good storage and voiding functions.
A

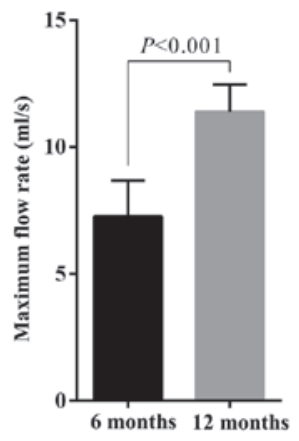

C

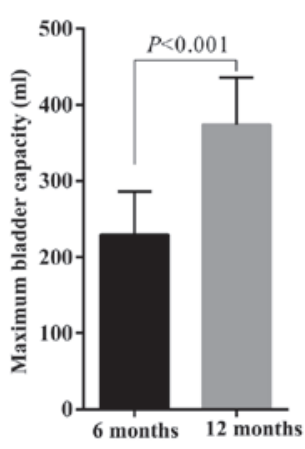

$\mathbf{E}$

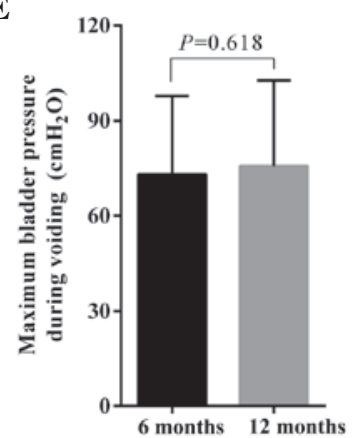

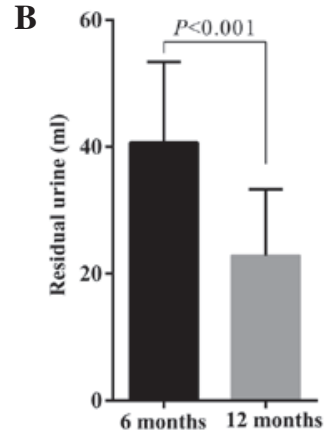

D

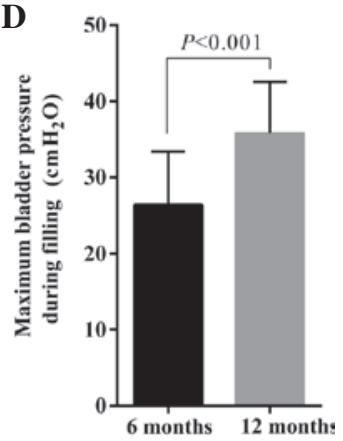

$\mathbf{F}$

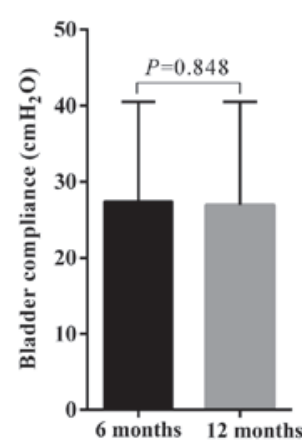

Figure 2. Urodynamic test results at 6 and 12 months post-surgery. (A) Maximum flow rate; (B) residual urine; (C) maximum bladder capacity; (D) maximum bladder pressure during filling; (E) maximum bladder pressures during voiding; and $(\mathrm{F})$ bladder compliance.

\section{Discussion}

Bladder cancer is one of the most common malignancies, and has become the most expensive to treat on a per-patient basis (13). Due to the extreme severity and metastasis-prone nature, bladder cancer patients have a poor prognosis and high mortality rate. Although the treatment of bladder cancer is complex, surgery remains generally acknowledged as the most effective treatment (14). Currently, radical cystectomy is widely used for muscle-invasive bladder cancer treatment, particularly for bladder cancer with T-staging $>2$. With the continuous improvement of surgical techniques and the wide application of advanced auxiliary equipment, there have been a number of studies documenting novel surgical approaches for bladder cancer (15-17), including laparoscopic radical cystectomy with orthotopic ileal neobladder, and due to the successful reconstruction of the neobladder, the post-operative quality of life of these patients has been greatly improved in recent years. 
Although urinary diversion following radical cystectomy can be carried out in several ways, orthotopic neobladder has been recognized as a relatively effective surgery (19). Besides avoiding the occurrences of urine and stool mixing and urine extravasation, the physiological function of the orthotopic bladder is also extremely close to the original bladder compared with other traditional urinary diversion surgeries (20). Considering the functional association between the bladder and bowel, the potent clinical application values of orthotopic ileal neobladder following radical cystectomy have been widely assessed (21-23). Currently, a program of strictly timed voiding has been carried out in all post-operative patients, which aids patients in establishing the storage and voiding functions of new bladders as soon as possible. However, significant differences remain in the biological characteristics and neural induction between the ileum and bladder. Long-term dynamic monitoring of neobladder function following surgery is important, and thus provides a basis for timely clinical intervention if abnormalities of the neobladder observed.

A normal lower urinary tract should be able to achieve efficient and low-pressure bladder filling, low-pressure urine storage with perfect continence and periodic complete voluntary urine expulsion, again at low pressure (24). In the present study, the orthotopic ileal bladder that was constructed exhibited a high capacity, improved compliance and low pressure at 6 months post-surgery. The residual urine content was also gradually reduced with the extension of the post-operative recovery time, which significantly contributed to the prevention of urinary tract infections. Moreover, the aforementioned functional parameters of the orthotopic ileal bladder were further improved at 12 months post-surgery. Thus, these findings further indicate the technical feasibility and improved long-term prognosis of the orthotopic ileal bladder, which is consistent with a previous study (25).

Studies have reported that the occurrence of night continence is $\sim 20 \%$, which is higher than that of day continence. Although the mechanism of night continence is not fully clarified, pelvic muscle relaxation, contraction of external sphincter and reservoir allantoic, and the lack of sensing urine expansion may be possible causes (26). In the present cohort, the ideal improvement in urodynamics during long-term follow-up may also be explained by the adequate level of health education and early bladder voiding function training, including timed voiding during the day and night, a balanced intake of water throughout the day and increased abdominal pressure using the hands (or a squatting posture) to maximize emptying of the bladder when urinating.

The limitation of the present study is the relatively small sample size, and consequently, large sample, multi-center studies are required. However, the dynamic monitoring data for the urodynamics reported in this study provide novel valuable evidence for the comprehensive evaluation of laparoscopic radical cystectomy with orthotopic ileal neobladder for bladder cancer in real life clinical practice.

\section{References}

1. Jemal A, Bray F, Center MM, Ferlay J, Ward E and Forman D: Global cancer statistics. CA Cancer J Clin 61: 69-90, 2011.

2. Kaplan AL, Litwin MS and Chamie K: The future of bladder cancer care in the USA. Nat Rev Urol 11: 59-62, 2014.
3. Botteman MF, Pashos CL, Redaelli A, Laskin B and Hauser R: The health economics of bladder cancer: a comprehensive review of the published literature. Pharmacoeconomics 21: 1315-1330, 2003.

4. Christoforidou EP, Riza E, Kales SN, et al: Bladder cancer and arsenic through drinking water: a systematic review of epidemiologic evidence. J Environ Sci Health A Tox Hazard Subst Environ Eng 48: 1764-1775, 2013.

5. Rodriguez Faba O, Gaya JM, López JM, et al: Current management of non-muscle-invasive bladder cancer. Minerva Med 104: 273-286, 2013.

6. Cheung G, Sahai A, Billia M, Dasgupta P and Khan MS: Recent advances in the diagnosis and treatment of bladder cancer. BMC Med 11: 13, 2013.

7. Clifton MM and Tollefson MK: Anatomic basis of radical cystectomy and orthotopic urinary diversion in female patients. Clin Anat 26: 105-109, 2013.

8. Kübler H and Gschwend JE: Ileal neobladder in women with bladder cancer: cancer control and functional aspects. Curr Opin Urol 21: 478-482, 2011.

9. Aboumarzouk OM, Drewa T, Olejniczak P and Chlosta PL: Laparoscopic radical cystectomy: a 5-year review of a single institute's operative data and complications and a systematic review of the literature. Int Braz J Urol 38: 330-340, 2012.

10. Huang J, Lin T, Xu K, et al: Laparoscopic radical cystectomy with orthotopic ileal neobladder: a report of 85 cases. J Endourol 22: 939-946, 2008

11. Challacombe BJ, Bochner BH, Dasgupta $\mathrm{P}$, et al: The role of laparoscopic and robotic cystectomy in the management of muscle-invasive bladder cancer with special emphasis on cancer control and complications. Eur Urol 60: 767-775, 2011.

12. Theofrastous JP, Whiteside J and Paraiso MF: The utility of urodynamic testing. J Am Assoc Gynecol Laparosc 10: 548-552, 2003.

13. Mossanen M and Gore JL: The burden of bladder cancer care: direct and indirect costs. Curr Opin Urol: May 30, 2014 (Epub ahead of print).

14. Mueller J, Schrader AJ, Schrader M, Schnoeller T and Jentzmik F: Management of muscle-invasive bladder cancer. Minerva Urol Nefrol 65: 235-248, 2013.

15. Azzouni F: Current status of minimally invasive radical cystectomy: an outcome-based comparison. Exp Rev Anticancer Ther 13: 681-695, 2013

16. Nix J, Smith A, Kurpad R, Nielsen ME, Wallen EM and Pruthi RS: Prospective randomized controlled trial of robotic versus open radical cystectomy for bladder cancer: perioperative and pathologic results. Eur Urol 57: 196-201, 2010.

17. Izquierdo L, Bolton DM and Lawrentschuk N: Radical cystectomy and orthotopic bladder substitution: surgical tricks and management of complications. Minerva Urol Nefrol 65: 225-234, 2013

18. Berger A and Aron M: Laparoscopic radical cystectomy: long-term outcomes. Curr Opin Urol 18: 167-172, 2008.

19. Roghmann F, Becker A, Trinh QD, et al: Updated assessment of neobladder utilization and morbidity according to urinary diversion after radical cystectomy: A contemporary US-population-based cohort. Can Urol Assoc J 7: E552-E560, 2013.

20. Herdiman O, Ong K, Johnson L and Lawrentschuk N: Orthotopic bladder substitution (Neobladder): part II: postoperative complications, management, and long-term follow-up. J Wound Ostomy Continence Nurs 40: 171-180, 2013.

21. Hart S, Skinner EC, Meyerowitz BE, Boyd S, Lieskovsky G and Skinner DG: Quality of life after radical cystectomy for bladder cancer in patients with an ileal conduit, cutaneous or urethral kock pouch. J Urol 162: 77-81, 1999.

22. Guan Z, Li J and Yang R: Impacts of different grafts for bladder reconstruction on postoperative recovery of the patients. Nan Fang Yi Ke Da Xue Xue Bao 33: 1250-1252, 2013 (In Chinese).

23. Marim G, Bal K, Balci U, Girgin C and Dinçel C: Long-term urodynamic and functional analysis of orthotopic ' $\mathrm{W}$ ' ileal neobladder following radical cystectomy. Int Urol Nephrol 40: 629-636, 2008.

24. Chapple C: Overview on the lower urinary tract. Handb Exp Pharmacol 202: 1-14, 2011.

25. Chen Z, Lu G, Li X, et al: Better compliance contributes to better nocturnal continence with orthotopic ileal neobladder than ileocolonic neobladder after radical cystectomy for bladder cancer. Urology 73: 838-844, 2009.

26. Schrier BP, Laguna MP, van der Pal F, Isorna S and Witjes JA: Comparison of orthotopic sigmoid and ileal neobladders: continence and urodynamic parameters. Europ Urol 47: 679-685, 2005 . 